\title{
Gênero na matemática escolar: um ato de resistência política
}

\author{
Elenilton Vieira Godoy ${ }^{1}$ \\ Fernanda Dartora Musha ${ }^{2}$ \\ Yasmin Cartaxo Lima ${ }^{3}$ \\ Marcio Antonio da Silva 4
}

\section{RESUMO}

De onde menos se poderia imaginar - aulas e livros de matemática - é possível discutir temas relacionados a gênero, subvertendo a lógica conservadora que busca abafar até a morte essas discussões. Sim, a matemática pode ser uma disciplina escolar estratégica para que a nãoneutralidade dos currículos se manifeste colocando em movimento ações de contraconduta às relações de poder postas pelo conservadorismo de certas parcelas da sociedade brasileira. Por intermédio de alguns exemplos que apresentam resultados de investigações realizadas por pesquisadorxs de duas universidades públicas brasileiras, pretende-se responder à questão: $\mathrm{O}$ que pode um currículo de matemática, no que concerne às discussões sobre questões de gênero? Esses exemplos deveriam ser reverberados, sempre que possível, nos espaços escolar e de formação de docentes que ministram matemática intencionando experienciar situações em que a matemática possa conflitar em vez de consensuar, neste caso, a dominação masculina e o arquétipo submisso e recatado da mulher.

PALAVRAS-CHAVE: Gênero. Livro Didático. Matemática Escolar. Estudos Culturais.

\footnotetext{
${ }^{1}$ Doutor em Educação. Universidade Federal do Paraná (UFPR). Curitiba. Paraná. Brasil. https://orcid.org/0000-00018081-5813.elenilton@ufpr.br.

${ }^{2}$ Mestranda em Educação. Universidade Federal do Paraná (UFPR). Curitiba. Paraná. Brasil. https://orcid.org/00000001-6431-1009. fernanda.musha@gmail.com.

${ }^{3}$ Mestranda em Educação. Universidade Federal do Paraná (UFPR). Curitiba. Paraná. Brasil. https://orcid.org/00000002-4272-2832.yasclima@gmail.com.

${ }^{4}$ Doutor em Educação Matemática. Universidade Federal do Mato Grosso do Sul (UFMS). Campo Grande. Mato Grosso do Sul. Brasil. https://orcid.org/0000-0002-5061-8453.marcio.ufms@gmail.com.
} 


\title{
Gender in Mathematics an act of political resistance
}

\begin{abstract}
In an unexpected place - math's classes and books - it is possible to discuss gender issues, subverting the conservative logic that seeks to stifle these discussions. Yes, mathematics can be a strategic school discipline so that the non-neutrality of curriculum manifest, setting in motion counterconduct actions to the power relations stablished by the conservatism of certain portions of Brazilian society. Through some examples that present the results of research carried out by researchers from two brazilian public universities, we intend to answer the question: What can a mathematics curriculum do, regarding discussions about gender issues? These examples should be reverberated, wherever possible, in the school and mathematics' teacher education, eith the intention to experience situations in which mathematics may conflict rather than consensus, in this case, with male domination and women's submissive and modest archetype.
\end{abstract}

KEYWORDS: Gender. Textbooks. Mathematics. Cultural Studies.

Género en las matemáticas escolares: un acto de resistencia política

\section{RESUMEN}

De donde menos podría imaginarse - clases y libros podrían imaginarse es posible discutir asuntos relacionados al género, subvirtiendo la lógica conservadora que busca sofocar estas discusiones hasta la muerte. Sí, las matemáticas pueden ser una disciplina escolar estratégica para que la noneutralidad de los planes de estudio se manifieste, colocando en marcha acciones de contraconducta a las relaciones de poder puestas por el conservadurismo de ciertas partes de la sociedad brasileña. Por intermedio de algunos ejemplos que presentan resultados de investigaciones llevadas a cabo por investigadores das universidades públicas brasileñas, se pretende responder a la cuestión: qué es lo que puede hacer un plan de estudios de matemáticas, con respecto a las discusiones sobre la cuestión de género? Esos ejemplos deberían ser reverberados, siempre que sea posible, en los espacios escolares y de formación de profesores que enseñan matemáticas, con la intención de experimentar situaciones en que las matemáticas puedan colocar en conflicto en vez de consensuar, en este 
caso, la dominación masculina y el arquetipo sumiso y recatado de la mujer.

PALABRAS CLAVE: Género. Libros de texto. matemáticas de la escuela. Estudios culturales.

\section{Prólogo}

FIGURA 1: Jair Bolsonaro na "Marcha para Jesus"

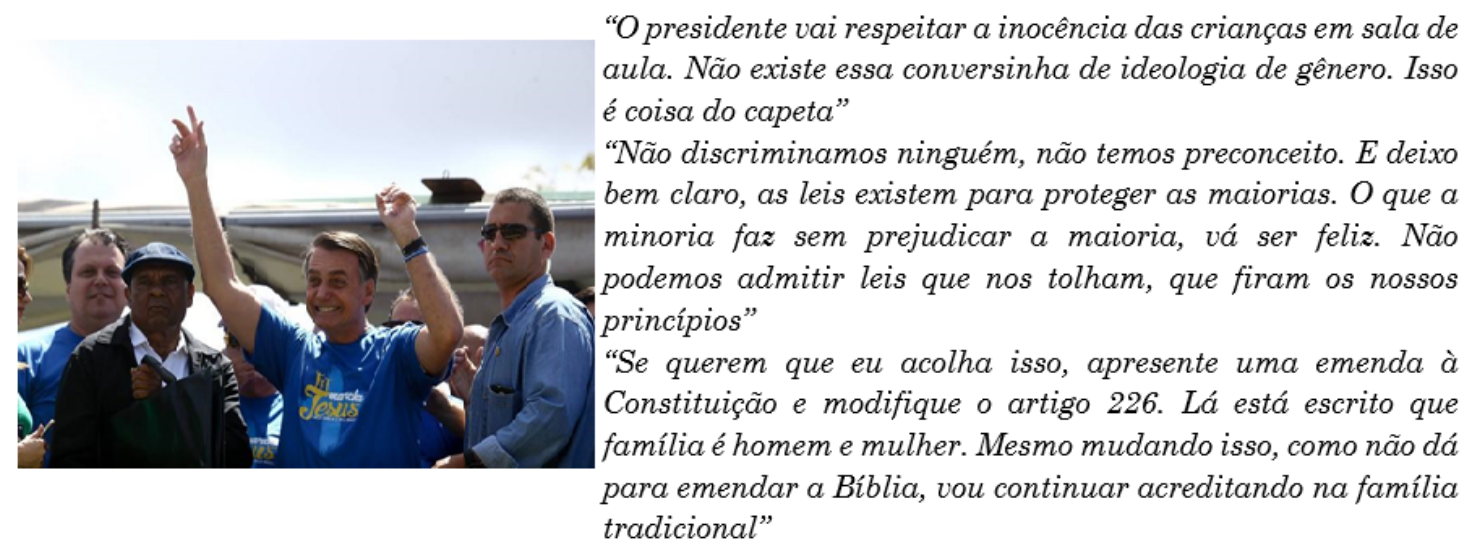

Jair Bolsonaro - 10 de agosto de 2019

Fonte: Pedro Ladeira/Folhapress (2019)

As frases, apresentadas no início deste artigo, foram pronunciadas pelo presidente da República, durante a realização da "Marcha para Jesus", em Brasília, no dia 10 de agosto de 2019. Elas são parte de um discurso conservador que ganhou força nos últimos anos, no Brasil e em vários outros países do mundo. Entre outras coisas, esse discurso ignora as conquistas de grupos minoritários e movimentos sociais que lutam por representatividade, visibilidade e igualdade de direitos.

Esse conservadorismo que ganha força no Brasil também produz impacto na educação: filosofia e sociologia têm a sua importância colocada em xeque por políticos que defendem a suposta neutralidade do currículo. Por esse viés, disciplinas das ciências humanas são consideradas menos importantes, ao contrário da matemática, por exemplo, que goza de um estatuto privilegiado nessa lógica direitista, pois é considerada neutra e 
potente para a formação de mão de obra qualificada para desenvolver tecnologias de ponta.

Neste artigo, defendemos que, de onde menos se poderia imaginar - as aulas e os livros de matemática -, é possível discutir temas relacionados a gênero, subvertendo a lógica conservadora que busca abafar até a morte essas discussões, pois “[...] algumas vezes não é uma questão de primeiro ter o poder e então ser capaz de agir; algumas vezes é uma questão de agir, e na ação, reivindicar o poder de que se necessita" (BUTLER, 2018, p.65). Sim, a matemática pode ser uma disciplina escolar estratégica para que a nãoneutralidade dos currículos se manifeste e coloque em movimento ações de contraconduta às relações de poder postas pelo conservadorismo de certas parcelas da sociedade brasileira.

Assim, por intermédio de alguns exemplos que apresentam resultados de investigações realizadas por pesquisadorxs da Universidade Federal do Paraná (UFPR) e da Universidade Federal de Mato Grosso do Sul (UFMS), pretendemos responder à questão: $\mathrm{O}$ que pode um currículo de matemática, no que concerne às discussões sobre questões de gênero?

As discussões sobre gênero no campo da educação matemática não são novas. O que é novo é a importância estratégica de tematizar esse assunto nas aulas de matemática, dada a configuração política que vivemos atualmente no Brasil. Desse modo, tomamos a explicitação das discussões sobre gênero nas aulas de matemática como um ato político potente, o qual pode resultar em um embate, uma luta para que se explicitem e que sejam denunciados preconceitos e estereótipos machistas aos quais as mulheres são expostas e que as colocam em uma posição de inferioridade em relação aos homens.

\section{Ato 1: Do natural ao estranhamento}

A matemática escolar é, com certa frequência, tratada como uma disciplina neutra, pois, invariavelmente, é trabalhada em sala de aula de 
modo descontextualizado, despersonalizado e despersonificado (GODOY, 2002). E mais, uma parte da população de docentes e futuros membros dessa comunidade que lecionarão a matemática escolar considera que a contextualização e a interdisciplinaridade devem ser associadas à história da matemática, às ciências da natureza e às engenharias, mas não às ciências humanas. Mas por que não associar à matemática escolar às ciências humanas? Qual é o grande mito, tabu?

A falta de familiaridade com a área inicialmente parece uma boa resposta - afim de deixar que a área seja abordada por quem a conhece com profundidade -, mas afinal qual é o conhecimento de docentes de matemática sobre ciências da natureza e engenharias? Outra resposta, comumente dada, seria que aplicações em assuntos não dominados por docentes banalizam a matemática, sendo assim rechaçadas.

Discursivamente, nenhuma resposta se sustenta, ou melhor, resiste à crítica, contudo, a proposta não é (será) apresentar argumentos que poderiam invalidar cada uma das possíveis respostas, mas sim, na medida do possível, desnaturalizar o fato de que não há outra saída senão aceitar que a matemática escolar é assim mesmo, descontextualizada, despersonalizada e despersonificada.

Em outro momento, escrevemos que a desconfiança deveria ser uma característica pulsante nas comunidades discente e docente (GODOY, 2015).

E ainda consideramos que o desconfiar precisa acompanhar tanto discentes quanto docentes, contudo, para além dele, o estranhar, como antagônico ao naturalizar-normalizar também precisa ser verbalizadoreverberado nas aulas da matemática escolar. Com a pretensa intenção de estranhar em vez de naturalizar-normalizar, conflitar em vez do consensuar o presente artigo tem como objetivo colocar em evidência dois elementos que fazem parte dos intramuros das salas de aulas da matemática escolar - o livro didático e a própria aula de matemática -, que podem oportunizar a discussão sobre questões que afligem a sociedade contemporânea. No presente artigo a temática evidenciada será a questão do gênero. 
Para isso, inicialmente será apresentado um excerto teórico a respeito da temática do artigo. Na sequência será elucidada a situação 'livro didáticomatemática-gênero' e, posteriormente, a situação 'aula de matemáticagênero'.

\section{Cena 1: Excertos teóricos sobre gênero-livro didático de matemática}

O material curricular 'livro didático', não raramente, é protagonista nas aulas da matemática escolar, uma vez que exerce - no tempo-presente do cenário educacional - papel essencial no cotidiano do trabalho docente. Compreendido como um artefato cultural, o livro didático influencia a experiência escolar em suas distintas dimensões (GARCIA, 2013) e provoca "debates no interior da escola, entre educadores, alunos e suas famílias, assim como em encontros acadêmicos, em artigos de jornais, envolvendo autores, editores, autoridades políticas, (...)" (BITTENCOURT, 2004, p. 471, apud SILVA; GODOY, 2018, p. 160).

Esse protagonismo pode ser observado também pelo fato de que "em diversas escolas da rede pública de ensino, o livro didático é [acaba sendo] o único material impresso para utilização em sala de aula" (FRISON et al, 2009, apud SILVA; GODOY, 2018, p. 160).

O protagonismo do livro didático, não raramente, presente no trabalho docente da matemática escolar, reforçado pelos interlocutores que, timidamente, anunciamos, nos inquieta. Inquietação produzida pelo silenciamento de discussões envolvendo contextos sócio-político-econômicocultural que, frequentemente, são oportunizados nas aulas e nos livros de didáticos de matemática, mas que acabam sendo naturalizados, invisibilizados.

Em tempos em que as disciplinas escolares - que, naturalmente, constroem suas aulas dialogando com esses contextos - são perseguidas e correm o risco de sumirem das escolas públicas brasileiras, a matemática escolar pode (e deve) lançar-se ao ataque e explicitar que, sim, é possível bradar nos intramuros das salas de aulas uma ou várias matemáticas que se 
mistura(m)-confunde(m) com o social, o político, o econômico, o cultural, ... (sem, todavia, banalizar o conhecimento matemático e as questões da contemporaneidade).

Aqui se faz uma presença urgente ao livro didático, à aula, à pessoa docente de matemática, qual seja a de visibilizar a contemporaneidade (relações de gênero, raça, etnia, sexualidade,...) que a virada cultural conservadora pretende guetificar.

No presente artigo escolhemos a-guetificar as relações de gênero nos intramuros das aulas da matemática escolar. O nosso desejo é reforçado pela importância dada ao livro didático como formador de valores que "configuram concepções de conhecimentos, de valores, identidades e visões de mundo" (FRISON et al., 2009, p.4), podendo ser visto como um reflexo da sociedade. Tendo em vista a importância desse material curricular, torna-se relevante analisar como nele estão dispostas as relações de gênero, pois tais representações podem servir de modelo para os estudantes no processo de construção de suas identidades (CASAGRANDE; CARVALHO, 2006).

Primeiramente, há a barreira de linguagem sexista ainda predominante. Silva (2004) ressalta a invisibilização provocada por essa linguagem que é comumente utilizada. Nos livros didáticos utilizados como referência no $2^{\circ}$ Ato é comum termos enunciados que não especificam o sexo das personagens, sendo o masculino sempre o utilizado: os jogadores, os políticos, o piloto, os funcionários. A representatividade feminina da generalização no masculino é nula.

Alves (2004) afirma que a linguagem sexista não apenas reforça, mas legitima a dominação masculina. O autor reflete o machismo em ditos populares, piadas, palavrões: a posição feminina é relativizada e normatizada, pois todos esses se baseiam no modelo assimétrico de hegemonia masculina. A mulher tem menor inserção política, social e cultural na hierarquização - supostamente natural - que a coloca em segundo lugar. Ele ainda afirma a necessidade de problematização dos vícios de linguagem, pois - para uma sociedade igualitária, ainda distante - é preciso reelaborar 
discursos e representações de gênero.

Não apenas a linguagem, as figuras que cercam discentes ajudam na perpetuação da desigualdade de gênero. Casagrande e Carvalho (2006) fizeram a análise de livros didáticos de matemática do início das décadas de 1990 e 2000 da $5^{\text {a }}$ e $6^{\mathrm{a}}$ séries. Considerando a importância dessa ferramenta para os processos de ensino e de aprendizagem, as autoras buscaram as representações apresentadas nos livros e que poderiam servir de modelos para a construção e definição da identidade discente. Para elas, a diferença entre as representações de gênero dos dois períodos analisados foi pouca: mantém-se a forma distinta que contribui para a socialização diferenciada de meninas e meninos. Meninos, mais frequentemente representados, têm autonomia e espírito aventureiro, enquanto meninas aparecem com comportamento passivo e relacionadas ao cuidado com a família e afazeres domésticos.

Posto isso, diversas instâncias atuam como possíveis constituintes de uma pedagogia cultural; dentre elas, a escola atua como um espaço de legitimação de ideologias sociais e culturais, porém, de forma discreta, de modo a fazer com que pensemos que a sociedade em que vivemos é justa e natural (LOURO, 2019; APPLE, 1989).

Para Butler (2019, p. 56), gênero é um conjunto de atributos flutuantes com efeito performativamente produzido e "imposto pelas práticas reguladoras da coerência de gênero", tendo o poder operando na produção da estrutura binária (masculino-feminino) em que se pensa tal conceito. Dessa forma, é impossível separar a noção de gênero dos embates políticos e culturais nos quais ele é produzido e mantido. Os chamados 'gêneros inteligíveis', aqueles que estão em estado de coerência e continuidade entre sexo, gênero, prática sexual e desejo, acabam assumindo o lugar de 'real', consolidando e incrementando "sua hegemonia por meio de uma autonaturalização apta e bem-sucedida" (BUTLER, 2019, p. 69). Dessa forma, os 'gêneros inteligíveis' da nossa cultura ocidental seriam os homens brancos e heterossexuais, e todos aqueles que têm sua expressão de gênero incoerente 
com a norma cultural imposta, têm a sua existência questionada (BUTLER, 2019).

Tendo em vista tais gêneros inteligíveis, construídos sob uma perspectiva heteronormativa, são produzidos padrões de como deve ser o comportamento de um menino ou menina. Se, por exemplo, uma garota gosta de jogar futebol, comportamento normalmente atribuído ao gênero masculino, ela poderá sofrer discriminação e ser desencorajada a praticar tal esporte. Tais atribuições de gênero também ocorrem no campo das ciências, sendo as ciências exatas uma área normalmente representada por figuras masculinas, escapando da tal neutralidade que lhe é conferida (LINS; MACHADO; ESCOURA, 2016). Os livros didáticos, não só de matemática, acabam tendo papel fundamental na reprodução de padrões de gêneros, pois a "coerção é introduzida naquilo que a linguagem constitui como domínio imaginável do gênero" (BUTLER, 2019, p. 131).

A forma celebrativa como são tratadas as diferenças nos livros didáticos tem o problema de não questionar as relações de poder que atuam na produção de tais distinções, gerando novas dicotomias, como "a do dominante tolerante e do dominado tolerado ou da identidade hegemônica, mas benevolente e da identidade subalterna, mas respeitada” (SILVA, 2009, p. 98). É necessário entender e trazer à sala de aula discussões do porquê certos padrões são considerados os 'normais-naturalizados' na sociedade em que vivemos e como eles foram construídos. Essa análise histórico-cultural ajuda a compreender a atual situação em que vivemos e constrói um pensamento crítico acerca de identidade de gênero (LOURO, 2011; MAIA et al., 2012). A falta de discussões, como essas, leva à reprodução de desigualdades e preconceitos dentro do ambiente escolar (ALMEIDA; LUZ, 2014).

\section{Ato 2: Livro Didático-Matemática-Gênero}

A partir daqui, apresentaremos alguns resultados de análises feitas por pesquisadorxs de dois Programas de Pós-Graduação em coleções de livros didáticos dos anos iniciais (UFMS) e dos anos finais (UFPR) do ensino 
fundamental. Essas pesquisas descreveram como livros didáticos de matemática direcionam tipos específicos de comportamentos desejáveis. Em outras palavras, como os livros também ensinam a ser homem ou mulher na nossa sociedade.

Nas investigações realizadas por pesquisadorxs da UFPR, os livros utilizados foram os de matemática dos $6^{\circ}$ e $9^{\circ}$ anos do Ensino Fundamental (EF II) de Centurión \& Jakubovic (2015), aprovados no PNLD de 2017 (ainda em vigência). A escolha dos anos se deu, por serem eles, as etapas inicial e final do EF II. O objetivo da análise foi investigar como a questão de gênero aparece no livro didático de matemática do EF II. Essa pesquisa foi publicada integralmente no e-book resultante do evento SIGESEX, realizado em 2019 pela UFMS (GODOY; LIMA; MUSHA, 2019).

Para isso, xs pesquisadorxs analisaram quantitativamente imagens com representações humanas e, dentre essas, àquelas que reforçam os estereótipos de gênero e quais vão contra. Além disso, quantificaram o número de representações de pessoas pensando, perguntando ou respondendo, de professores, de professoras e de igualdade de gêneros. Com base na bibliografia utilizada, também investigaram de forma qualitativa tais imagens, separando algumas que chamaram mais atenção no sentido de manutenção ou de oposição a estereótipos de gênero para uma análise mais concreta. O primeiro resultado obtido está organizado no Quadro 1.

Quadro 1: Imagens com representações humanas

\begin{tabular}{|l|c|c|}
\hline CATEGORIAS & Quant. & Percentual \\
\hline Reforçam o estereótipo & 34 & $17,5 \%$ \\
\hline Combatem o estereótipo & 8 & $4,1 \%$ \\
\hline Pensando, perguntando ou respondendo (gênero masculino) & 33 & $17,0 \%$ \\
\hline Pensando, perguntando ou respondendo (gênero feminino) & 26 & $13,4 \%$ \\
\hline Professores & 16 & $8,2 \%$ \\
\hline Professoras & 8 & $4,1 \%$ \\
\hline Igualdade de gêneros & 69 & $35,6 \%$ \\
\hline TOTAL & 194 & $100,0 \%$ \\
\hline
\end{tabular}

Fonte: Os autores (2019) 
Em relação ao Quadro 1, percebemos que os livros didáticos analisados, por meio de suas imagens de representação humana, têm se preocupado em movimentar sentidos a respeito da igualdade de gêneros, todavia, o caminho é longo, uma vez que ainda precisamos conflitar os estereótipos que reforçam os papéis desempenhados, tradicionalmente, por mulheres e homens no Brasil. A mulher, invariavelmente, está associada à moda, família, cuidados da casa, planejamento de festas, culinária e trabalhos manuais mais delicados, como origami; e o homem ao carregamento de peso, práticas de esportes, encarregado de serviços gerais de reforma e até dirigindo. O homem é uma figura imponente, aventureira e detentora de poder, usualmente vista fora de casa, enquanto a mulher é delicada, feminina e é responsável pelos afazeres da casa, tais como as compras do mês. Quase não há imagens que retratam mulheres em lugares de prevalência masculina - motogirl, atletas, jogatina -, e homens dividindo espaço com mulheres em atividades manuais - dobradura, recorte e desenho. Por fim, percebemos na análise, que não há o domínio masculino da fala e do conhecimento - mulheres também são questionadoras e detentoras do conhecimento.

Para ilustrar algumas dessas situações foram selecionadas quatro imagens, sendo três do livro do $6^{\circ}$ ano e uma do livro do $9^{\circ}$ ano.

FIGURA 2: Mulher às Compras FIGURA 3: Mulher cozinhando para as crianças

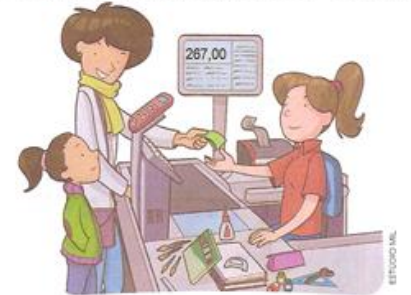

Fonte: Centuríon e Jakubovic (2015a, p.47)

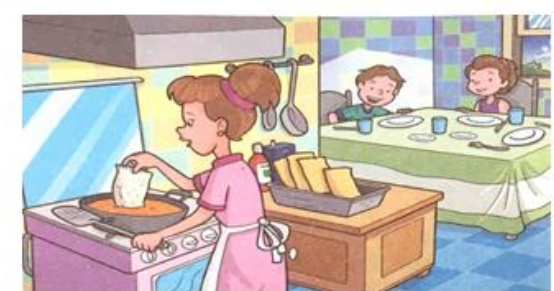

Fonte: Centuríon e Jakubovic (2015b, p.225)

Na Figura 2, há uma mulher com a filha comprando materiais escolares e outros itens - cadernos, tintas, pincéis, tesoura, cola, esquadro, transferidor. A caixa da loja, também mulher, recebe o dinheiro da mãe pelos itens. A imagem reproduz muitos estereótipos de gênero em uma situação simples: a 
mulher associada à imagem familiar e, como mãe, responsável por atender às necessidades da criança; a garota associada ao trabalho manual delicado, claro pelos itens comprados (materiais de pintura, desenho, recorte e colagem); a caixa da loja, como mulher, em um trabalho majoritariamente feminino. Não há a ocorrência de homens representados nessas situações, comuns para quem têm crianças, e nem como caixas de papelaria, supermercados etc. Há poucos garotos representados desenvolvendo trabalhos manuais. Mulheres continuam como alvo dessa representação: elas começaram a aparecer em áreas de prevalência masculina, mas eles continuam em seus lugares tradicionais. Naturalizar essas situações é reafirmar o papel da mulher da sociedade tradicional: esposa, mãe, cuidadora do lar, delicada, recatada.

$\mathrm{Na}$ Figura 3, pode-se observar mais uma representação estereotipada da figura feminina, nesse caso, a ilustração da mulher cozinhando para as crianças, com uma roupa "tipicamente" feminina, o vestido rosa. Em nenhum dos livros didáticos encontramos imagens de homens realizando tarefas domésticas (cozinhando, limpando a casa, cuidando das crianças, entre outras), reforçando que esse tipo de atividade é "restrito" à mulher.

FIGURA 4: Crianças brincando na praia e mulheres praticando atletismo

Fonte: Centuríon e Jakubovic (2015a, p.225 e 50)

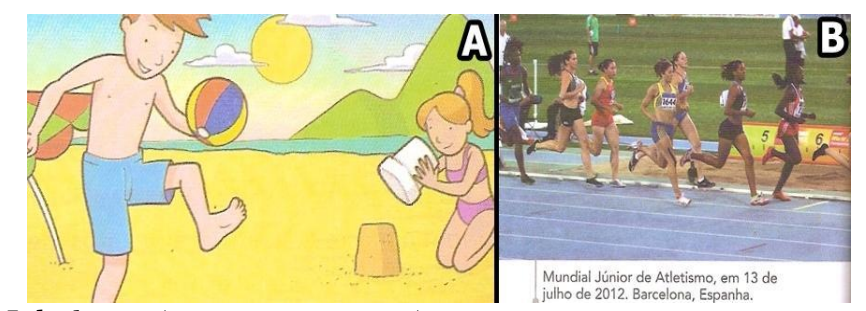

Observa-se na Figura 4-A duas crianças brincando na praia. Inicialmente, destacamos o estereótipo da cor das roupas usadas pelas duas crianças, ou seja, o garoto com roupa na cor azul e a garota com a roupa cor de rosa. Um segundo ponto a ser destacado refere-se ao tipo de brincadeira de cada criança. $\mathrm{O}$ garoto, mais à frente da imagem, joga bola, enquanto a garota constrói esculturas de areia ao fundo. Reforça-se a ideia do garoto bom em 
esportes e da garota graciosa e com gosto pelos trabalhos manuais delicados. Garotas têm pouco incentivo para a prática de esportes, considerando as modalidades femininas invisibilizadas e as atletas pouco reconhecidas. Um exemplo disso é a Copa do Mundo de Futebol Feminino, que, em 2018, teve sua premiação aumentada pela FIFA para US $\$ 30$ milhões, porém a competição masculina chegou a ter uma premiação de US $\$ 400$ milhões em sua última edição (PAULINO, 2018). Tendo isso em vista, a Figura 4-B, do Mundial Júnior de Atletismo de 2012, é de grande importância para uma representatividade positiva que vai de encontro aos estereótipos de gênero.

A pesquisa realizada por Deise Souza, junto ao Programa de PósGraduação em Educação Matemática da UFMS (em andamento), analisou 103 livros didáticos de matemática dos anos iniciais das coleções aprovadas no Plano Nacional do Livro Didático (PNLD) de 2016, sendo 69 de alfabetização matemática ( $1^{\circ} ; 2^{\circ}$ e $3^{\circ}$ anos) e 34 de matemática ( $4^{\circ}$ e $5^{\circ}$ anos).

Em uma análise específica sobre como os livros de matemática apresentam brinquedos como tema atrativo para se ensinar matemática, Deise Souza identificou uma regularidade discursiva do que poderíamos classificar como brinquedos e brincadeiras "de menino" e "de menina".

Foram 528 figuras que apresentavam alguma forma de interação criança-brinquedo ou criança-brincadeira. O Quadro 2 a seguir mostra um importante resultado da pesquisa:

Quadro 2: Interação criança-brinquedo ou criança-brincadeira

\begin{tabular}{|c|c|c|c|}
\hline $\begin{array}{c}\text { Tipos de } \\
\text { brinquedos }\end{array}$ & $\begin{array}{c}\mathbf{N}^{\mathbf{o}} \text { de imagens } \\
\text { com meninas }\end{array}$ & $\begin{array}{c}\mathbf{N}^{\mathbf{0}} \text { de imagens } \\
\text { com meninos }\end{array}$ & $\begin{array}{c}\mathbf{N}^{\mathbf{o}} \text { de imagens com } \\
\text { meninas e meninos }\end{array}$ \\
\hline Bonecas & 83 & 0 & 3 \\
\hline Bichos de pelúcia & 35 & 0 & 0 \\
\hline Bolas & 35 & 155 & 0 \\
\hline Boliche & 14 & 11 & 0 \\
\hline Bolhas de sabão & 2 & 0 & 0 \\
\hline Carrinhos & 3 & 117 & 0 \\
\hline $\begin{array}{c}\text { Jogo (figurinhas, } \\
\text { dardos) }\end{array}$ & 0 & 5 & 1 \\
\hline Bolinha de gude & 8 & 34 & 0 \\
\hline Pião & 0 & 4 & \\
\hline
\end{tabular}




\begin{tabular}{|c|c|c|c|}
\hline Super-heróis & 0 & 16 & 1 \\
\hline Videogame & 2 & 4 & 0 \\
\hline
\end{tabular}

Fonte: Adaptado de (VALERO; SILVA; SOUZA, 2019)

Além do que é evidenciado pelo Quadro 2, por exemplo, brincar de bola é atividade de menino e brincar de boneca é de menina, essas brincadeiras constroem e normalizam práticas sociais do que é esperado de um homem e de uma mulher.

FIGURA 5: Crianças brincando de boneca

Fonte: Silveira (2014, p. 244)

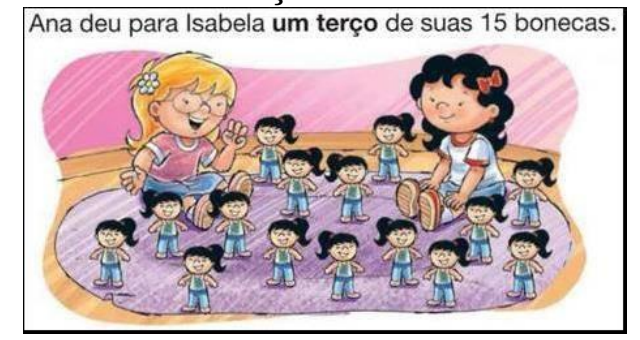

O brincar de boneca está ligado, em geral, ao cuidado, à atenção e à generosidade. Assim, ao ver Ana dando um terço de suas bonecas, a matemática da divisão e do cálculo com frações se relaciona com valores feminilizados, como o cuidado com o outro.

Ainda encontramos exceções, como no exemplo: "Sofia, irmã de Lucas, coleciona carrinhos, ela tinha 20 carrinhos e ganhou 5 em seu aniversário. Quantos carrinhos ela tem agora?” (MATRICARDI, 2014, p. 110).

No entanto, "Sofia" é apresentada como "irmã de Lucas" (o que nos parece uma justificativa para o fato de uma menina poder colecionar carrinhos: ter um irmão!). Essa parece uma estratégia discursiva para mostrar que existe uma certa pluralidade, e não regularidade, nas ações legitimadas como sendo de meninas e meninos. A nosso ver, exemplos como esse são o que Paul Dowling chamou de "ritual de genuflexão [ajoelhar, reverenciar] para o discurso da igualdade de oportunidades e para desarmar bombas antissexistas" (DOWLING, 1991, p. 4, tradução nossa), reforçando não as lutas sociais por igualdade, mas a própria diferenciação.

O currículo de matemática opera por intermédio de uma técnica muito 
refinada: dá uma suposta liberdade, mas, ao mesmo tempo, mostra modos específicos de ser. É o caso do exemplo a seguir, no qual o livro apresenta:

FIGURA 6: Vestindo xs bonecxs
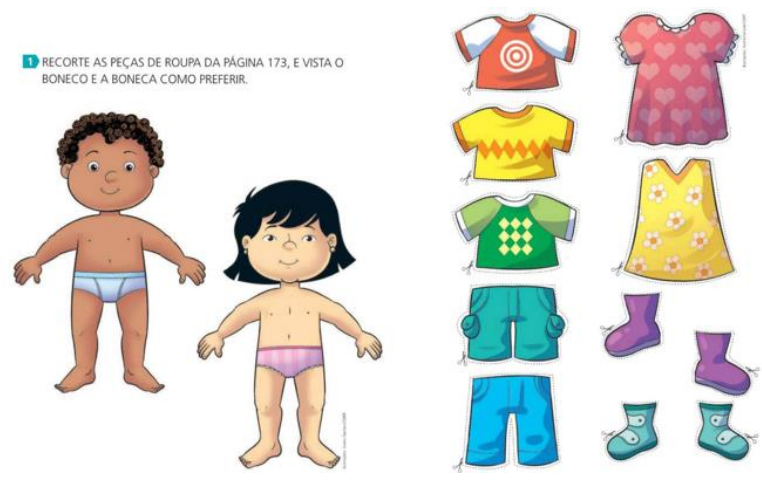

Fonte: Fonte: Nani (2014, p. 143 e 173)

A atividade convida o(a) estudante a vestir o boneco e a boneca "como preferir". Interessante notar que, mesmo com roupas íntimas, os bonecos já reproduzem modos de ser menino e menina (cueca azul e calcinha rosa).

A partir dessa pretensa liberdade, o livro propõe algumas soluções:

FIGURA 7: Modos de vestir o boneco

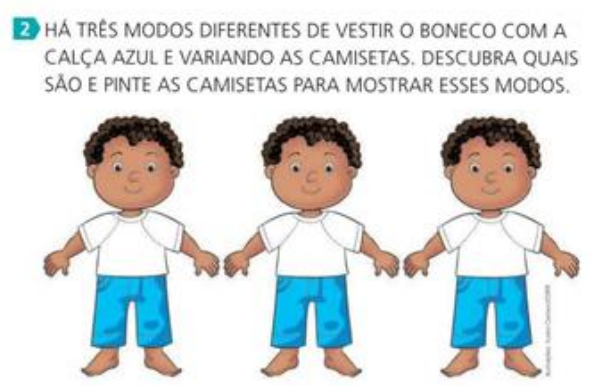

FIGURA 8: Modos de vestir a boneca

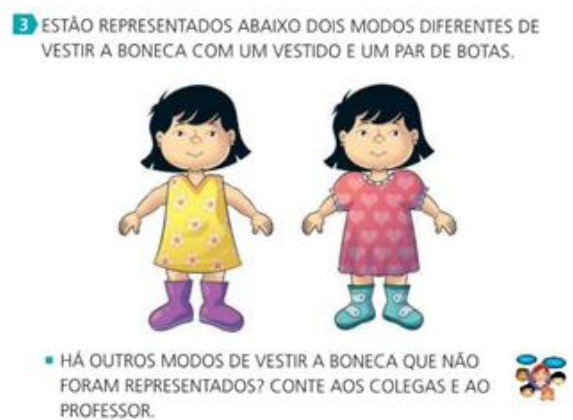

Fonte: Nani (2014, p. 143)

O livro propõe, sim, outras formas de se vestir o boneco, além das apresentadas. Mas o dispositivo que propõe, também exige a confissão: "conte aos colegas e ao professor". Essa técnica constrange e inibe, separando o que pode ser dito do que não pode ser dito.

A matemática das combinações não aceita todas as combinações. Há combinações idealizadas, combinações esperadas, combinações normalizadas 
para meninos e combinações normalizadas para meninas.

As pesquisas, descritas até aqui, movimentam um currículomatemática-gênero que opera um modo muito específico de ser menina e ser menino no mundo contemporâneo. A seguir, mostraremos como esse currículo também opera na aula de matemática.

\section{Ato 3: Aula de matemática-gênero ${ }^{5}$}

O relato de experiência que será apresentado, aborda a questão de gênero a partir da encenação de violências simbólicas comuns à sala de aula e a escolha se deu, tendo em vista o suposto distanciamento da matemática com temas da sociedade contemporânea.

Para tanto foi desenvolvida uma aula (com explicações no quadro de giz e resolução de exercícios) sobre probabilidade, com duração de 100 minutos (duas horas-aula) e a participação de aproximadamente 15 alunos (discentes e o professor da disciplina Matemática no Ensino Médio - MEM). A aula foi ministrada por uma aluna-professora e um aluno-professor caracterizados. $\mathrm{O}$ aluno-professor foi vestido de mágico e a aluna-professora foi vestida de ajudante do mágico (nos moldes das apresentações televisivas mais clássicas envolvendo mágicos e suas ajudantes). Em diversos momentos da aula, a dupla discente-docente e o professor-aluno (professor da disciplina MEM) agiram de forma propositalmente machista - em alguns momentos diretamente, por meio de falas, interrupções constantes a mulheres e liderança masculina; e em outros indiretamente, por omissão e discurso de questão. O objetivo do relato de experiência, bem como da aula aplicada foi expor os diversos machismos que ocorrem frequentemente em sala de aula e por vezes passam despercebido.

O comportamento - reproduzido na aula aplicada para posterior discussão - perpetua a naturalização da submissão da mulher,

\footnotetext{
${ }^{5}$ O Ato 3 faz parte do trabalho final de Fernanda Dartora Musha e Hoesller Luan Elias Portela, intitulado Gênero e Matemática: confluência ou dicotomia? apresentado a discentes da disciplina Matemática no Ensino Médio (MEM), do curso de licenciatura em Matemática da Universidade Federal do Paraná (UFPR). O trabalho final consistiu no planejamento e execução de uma aula de matemática sobre algum assunto do ensino médio.
} 
estereotipando-a como ser afetivo e frágil. O traje escolhido para a ajudante foi o típico utilizado por assistentes de mágicos: roupas curtas e apertadas, que sensualizam e deixam a mostra o corpo da mulher. A dominação masculina que se instituiu nos corpos femininos os tornam objetos simbólicos, fazendo com que a mulher exista, primeiro, para o olhar dos homens e que a dita feminilidade seja uma forma da mulher atender às expectativas masculinas (BOURDIEU, 2019). À mulher, não cabem as ciências exatas - no máximo a licenciatura, devido à sua vinculação com a ética do cuidado. Não há espaço de fala, e fica nítido quais profissões uma mulher deve ocupar. Carros e futebol são conhecimentos tipicamente masculinos, e à mulher resta a culinária e os afazeres domésticos. O arquétipo feminino é balizado e cerceado: o lugar da mulher está bem definido.

O material utilizado e entregue aos discentes foi uma folha de exercícios selecionados de alguns livros de matemática do ensino médio ${ }^{6}$. Algumas questões foram alteradas para que o nível de dificuldade fosse condizente com o conteúdo ministrado na aula; o teor das questões, contudo, se manteve: representações das figuras femininas e masculinas em seus respectivos papéis sociais.

\section{Cena 1: A aula per se}

Para iniciar a aula foi escolhido um desafio motivador (o problema de Monty Hall7). Depois disso, o aluno-professor, caracterizado de mágico, e a aluna-professora, caracterizada como ajudante do mágico, prosseguiram a aula com um número de mágica utilizando um baralho de cartas. Nota-se

\footnotetext{
${ }^{6}$ (YOUSSEF, FERNANDES \& SOARES, 2005; BARROSO, 2010; GIOVANNI \& BONJORNO, 2011; e BALESTRI, 2016).

7 Também conhecido como paradoxo de Monty Hall, trata-se de um problema matemático que surgiu a partir do concurso televisivo estadunidense "Let's Make a Deal". No programa da década de 1970, o apresentador Monty Hall mostrava três portas a concorrentes, sendo que atrás de uma delas havia um prêmio e das demais, um bode, simbolizando a perda da pessoa participante. A pessoa participante escolheria a porta em que achava que estava o prêmio, que continuaria fechada. Monty Hall então abriria uma das portas restantes, que conteria um bode, e não o prêmio. Após a eliminação de uma das portas, o apresentador pergunta se a pessoa participante deseja trocar a porta que inicialmente escolheu, uma vez que certamente o prêmio estará numa das duas portas restantes. A estratégia de trocar de porta tem $2 / 3$ de chance de acertar a porta premiada, uma vez que se tem duas possibilidades de escolher uma porta com um bode inicialmente e apenas uma de se escolher a porta premiada. Assim, em duas das três possibilidades de escolha inicial, troca-se a porta escolhida pela porta premiada. A probabilidade de acerto é maior que $1 / 2$, a chance de ganhar na escolha entre duas portas, uma com prêmio e uma com bode (GRANBERG \& BROWN, 1995).
} 
aqui que as roupas escolhidas foram representativas: a mulher com maquiagem, saia e camisa justa, e o homem de gravata, cartola e capa. A aluna-professora era apenas um acessório atrativo e o aluno-professor, centro das atenções e detentor do conhecimento. Durante a aula, a alunaprofessora foi apenas uma expectadora, enquanto o aluno-professor comandou a aula circense envolvendo mágica-e-probabilidade.

Após a exposição dos conceitos e propriedades básicas sobre a probabilidade, o aluno-professor apresentou e resolveu três exercícios com a turma; o primeiro deles sobre futebol, o segundo sobre fórmula 1 e terceiro sobre moda. O primeiro será apresentado a seguir para exemplificar o tipo de exercício selecionado.

FIGURA 9: Exercício envolvendo o binômio rapazes-futebol

EXERCíCIO l: Um time de futebol amador ganhou uma taça ao vencer um
campeonato. Os jogadores decidiram que o prêmio seria guardado na casa de um deles.
Todos quiseram guardar a taça em suas casas. Na discussão para se decidir com quem
ficaria o troféu, travou-se o seguinte diálogo:
PEDRO, CAMISA 6: - Tive uma ideia. Nós somos 11
jogadores e nossas camisas estão numeradas de 2 a 12 . Tenho dois dados
com as faces numeradas de 1 a 6. Se eu jogar os dois dados, a soma dos
números das faces que ficarem para cima podem variar de 2 (que é a
mesma coisa que 1+1) até 12 (que é a mesma coisa que $6+6$ ). Vamos jogar
os dados, e quem tiver a camisa com o número do resultado vai guardar
a taça.
TADEU, CAMISA 2: - Não sei não... Pedro sempre foi muito
esperto... acho que ela está levando alguma vantagem nessa proposta...
RICARDO, CAMISA 12: - Pensando bem... Você pode estar
certo, pois, conhecendo o Pedro, é capaz que ele tenha mais chances de
ganhar do que nós dois juntos...
Desse diálogo, conclui-se que:
a) Tadeu e Ricardo estavam equivocados, pois a probabilidade de ganhar a guarda da
taça era a mesma para todos.
b) Tadeu tinha razão e Ricardo estava equivocado, pois juntos tinham mais chances de
ganhar a guarda da taça do que Pedro.
c) Tadeu tinha razão e Ricardo estava equivocado, pois juntos tinham a mesma chance
que Pedro de ganhar a guarda da taça.

Fonte: Giovanni \& Bonjorno (2011, p. 157)

Os demais exercícios seguiram essa linha, com o exercício de fórmula 1 (Questão 2) perguntando sobre as posições de um piloto na corrida - com artigos masculinos - e o de moda (Questão 3) perguntando das combinações possíveis de roupas de Márcia, uma mulher. Os três exercícios foram escolhidos para evidenciar o discurso de questão comumente apresentado: a construção social de "coisas de homem" e "coisas de mulher", com mulheres associadas a roupas e homens a futebol e carros; e a linguagem sexista que 
generaliza piloto e competidores, remetendo a homens.

Uma discente-aluna pediu para realizar a leitura do diálogo da Questão 1 e, quando a aluna-professora afirmou que era um papel masculino, retrucou que Ricardo poderia ser uma garota. Com uma expressão desconfortável, a aluna-professora deixa a discente-aluna realizar a leitura, mas não conversa sobre o assunto. Outra discente-aluna, irritada com a falta de atenção, questiona xs alunxs-professorxs se a aula é só para os meninos, mas não obtém resposta.

O professor-aluno (professor de fato da disciplina, portando-se como aluno) comentou que a explicação do aluno-professor era melhor do que a da aluna-professora; ao ouvir isso, a aluna-professora senta e deixa o alunoprofessor comandar totalmente a aula.

Cabe destacar que antes da realização da prática pedagógica, fez-se um acordo com o professor-aluno para que fizesse comentários machistas, incluindo um roteiro feito pela dupla que ministrou a aula. $\mathrm{O}$ objetivo aqui era mostrar que, mesmo quando o machismo inicia com discentes, a omissão e falta de intervenção docente também é uma ação machista.

FIGURA 10: Frases do roteiro (professor-aluno)

- "A gente podia fazer um jogo aqui com o pessoal da sala, né. As
meninas ficam torcendo e podem até trazer um lanche pra gente, afinal,
a gente vai estar cansado depois do futebol" (Questão 1).
-As meninas não vão entender esse problema. Não sabem nada de
carros e não sabem nada de matemática. Como vão entender isso ai??"
(Questão 2).
-Essa questão não tem nada a ver, em que mundo que uma mulher
tem SÓ 4 pares de sapatos?" (Questão 3).
- "Vai ter trabalho em grupo? Se tiver, já tem meu grupo aqui com a
piazada, eles que manjam disso aí. As meninas não estão com nada".
- Caso alguma mulher se irrite e responda, "Você deve estar naqueles
dias".

Fonte: Os autores (2019)

Além do roteiro para o professor-aluno, havia um para a alunaprofessora e o aluno-professor (alunxs-professorxs). 
FIGURA 11: Frases do roteiro (alunxs-professorxs)

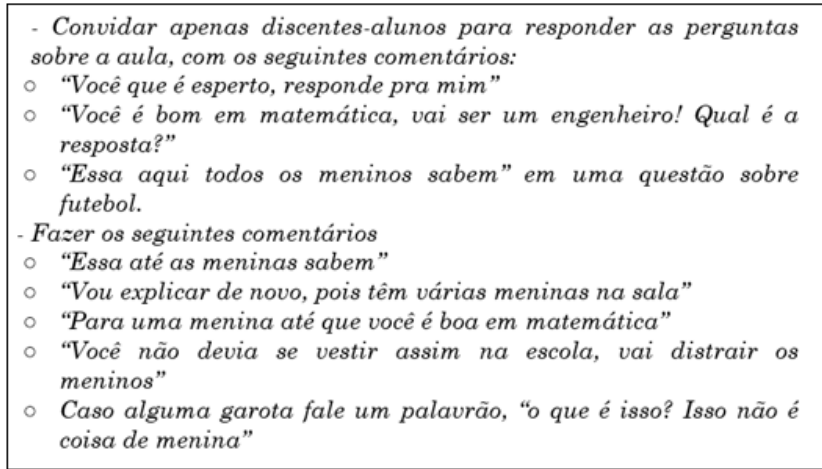

Fonte: Os autores (2019)

Cabe destacar que nenhum roteiro foi seguido à risca, mas a essência se manteve ${ }^{8}$.

Em toda a aula, o machismo perdurou: na fala da dupla que ministrou a aula e do professor-aluno, na omissão, no discurso de questão, nas interrupções constantes a mulheres. Nos momentos mais explícitos, algumas pessoas pareciam desconfortáveis, mas não houve reclamações além das citadas anteriormente. Algumas discentes-alunas esboçaram revolta, mas devido ao exemplo das duas colegas ignoradas, não se manifestaram.

A resolução de Monty Hall finaliza a aula, deixando a turma intrigada, pois, durante o semestre, foi anunciado que o tema da aula seria gênero.

\section{Cena 2: A discussão e o feedback após a aula}

Após a finalização, cada participante comentou sobre a aula. Diversos elogios à mágica e ao desafio motivador, bem como críticas à organização do quadro e à falta de mais registros escritos. Elogios à paciência para explicação de assuntos mais simples e ao interesse em sanar todas as dúvidas. O que se destacou, contudo, foram os questionamentos dos participantes: a aula não

\footnotetext{
${ }^{8}$ Ambos os roteiros tiveram inspiração na intervenção do Coletivo Feminista Zaha, de alunas da Faculdade de Arquitetura e Urbanismo e Faculdade de Design do Mackenzie, em São Paulo. O coletivo espalhou pela faculdade cartazes que traziam declarações machistas de docentes do curso feitas dentro da sala de aula, como "você fala muito palavrão, isso não é coisa de menina" e "agora vamos explicar de novo porque a sala tem muitas meninas". Todas as declarações tiveram ao menos duas testemunhas e foram expostas nos cartazes sem o nome das vítimas e dos acusados. O coletivo afirmou que o objetivo dessa ação foi evidenciar as situações sofridas pelas mulheres na universidade, permitindo a discussão entre corpo docente, discente e pessoas contratadas e ainda possibilitando a troca de experiências entre mulheres universitárias. As frases escritas pela dupla que ministrou a aula também já foram ouvidas em diversos ambientes - casa, escola, faculdade - por muitas mulheres (O GLOBO, 2018).
} 
seria sobre gênero? Para eles, foi apenas mais uma aula de probabilidade, o gênero foi deixado de lado.

Xs alunxs-professorxs então explicam que a questão de gênero estava lá o tempo todo, apenas com a manutenção da relação assimétrica de gênero. Relembrando os diversos momentos da aula, dá-se visibilidade aos machismos corriqueiros: o pouco (quase inexistente) espaço de fala da mulher; a construção social dos papéis feminino e masculino; a linguagem sexista invisibilizadora; as "piadas" e coerções às mulheres; a omissão frente ao machismo de outra pessoa. Todos esses pontos tomaram vida com a atitude da dupla discente-docente e do professor-aluno, além do discurso de questão: machismo falado, escrito e ignorado, porém em nenhum momento discutido. Em momento algum houve neutralidade, apenas reprodução da cultura androcentrista.

Algumas pessoas então confessaram não ter percebido tudo isso, mas outras relataram estranheza diante do silêncio da aluna-professora e do aluno-professor frente às provocações machistas do professor-aluno. Criou-se então uma discussão sobre os machismos presenciados diariamente - na família, na roda de amigos, na escola - e a necessidade de se conversar abertamente sobre o tema. Muitas ações que perpetuam as relações assimétricas de gênero são naturalizadas; perdura, portanto, o machismo que limita, diminui, agride e marginaliza mulheres. Não é necessário ir longe: o machismo mora ao lado, está na mesa de bar com amigos e amigas, no almoço de domingo em família, na sua aula favorita, basta prestar atenção.

\section{Ato 4: Gênero e os intramuros das aulas da matemática escolar: em revista}

Como elemento central das aulas de matemática, o livro didático pode tanto legitimar quanto questionar um discurso dominante nos intramuros da sala de aula. Os livros analisados, tanto dos anos iniciais, quanto dos anos finais do ensino fundamental não apresentam apenas o arquétipo submisso e recatado da mulher, mas também mulheres questionadoras, detentoras do 
saber e ocupando novos espaços e funções que, outrora, eram dominados por homens. A mulher é diversa, frequentemente está em ambientes masculinos, todavia, continua sendo alvo do machismo estrutural e dificilmente divide seu lugar concebido (o lar e seus afazeres, suas profissões típicas, suas atividades e interesses delicados) com o homem. Apesar desse avanço, ainda se faz necessário legitimar cada vez mais o espaço da mulher na sociedade contemporânea mediante representações assertivas que respeitem a pluralidade da mulher e do homem, bem como sua equidade.

O livro didático, possivelmente, o material curricular mais usado nas aulas da matemática escolar (mas não só nessa disciplina) pode fomentar discussões pertinentes sobre assuntos que extrapolem o conhecimento matemático, sem banalizá-lo; se faz necessário, contudo, que nós, docentes de matemática, enxerguemos para além da moldura do quadro, ou seja, para além daquela matemática escolar descontextualizada, despersonalizada e despersonificada.

A situação envolvendo a aula de probabilidade foi contextualizada, prendeu a atenção dos participantes, mas veladamente naturalizou o machismo. Neste sentido, a contextualização e a encenação - bem conduzida pela caracterização de mágico-ajudante da dupla que ministrou a aula legitimou, implicitamente, a dominação masculina e elucidou que a distração (fomentada pela encenação) pode enviesar e docilizar os sujeitos-alunos sobre a questão do gênero, perpetuando um discurso dominante branco-masculinohomofóbico.

Percebemos com a situação em questão que é comum as pessoas se indignarem com o machismo mais explícito - falas diretas sobre o lugar da mulher. As discentes da turma, constantemente interrompidas, sentiram a usurpação do seu espaço de fala: foram silenciadas. Apesar disso, os detentores da fala não a usaram para protestar - o que comumente acontece quando é presenciado o machismo de uma pessoa próxima.

Para a possibilidade de uma sociedade com equidade de gênero, é necessário questionar, estranhar e desnaturalizar essas condutas e 
experiências. Agentes de suma importância na formação de um indivíduo, docentes precisam revisitar-ressignificar- contestar as antigas, porém, ainda presentes, práticas sociais do modelo assimétrico que coloca o homem hierarquicamente no controle.

Os participantes da aula compreenderam a importância da discussão de gênero e da autofiscalização para evitar a reprodução de machismo. Urge a necessidade de frear a legitimação das desigualdades dicotômicas entre mulheres e homens, e as críticas feitas aqui são essenciais e podem contribuir para o pavimento de um caminho em direção a uma sociedade equânime, de mulheres empoderadas. O tradicional comportamento docente não é imparcial, pois o machismo parece intrínseco ao ambiente escolar. Dessa forma, é comprovada a alarmante necessidade de se falar de gênero nas escolas, principalmente, nas aulas de uma disciplina historicamente categorizada como neutra, a matemática escolar.

A matemática escolar entendida como uma prática social discursiva pode e deve produzir sentidos para além do seu corpus per se, mas tal significação somente ocorrerá se nós, docentes de matemática, sairmos da nossa gaiola didática-pedagógica e alçarmos voos maiores.

Nada disso ocorrerá de maneira espontânea, por isso, a importância de se evidenciar as duas situações propostas neste artigo. Elas e tantas outras já produzidas ou em produção devem ser reverberadas, sempre que possível, nos espaços escolares e de formações docentes que ministram matemática. Inicialmente, elas causarão desconforto, aversão, repulsa, mas num espaço dialógico-comunicativo tais sentimentos serão, aos poucos, superados e, a partir daí, será possível experienciar situações onde a matemática escolar possa conflitar em vez de consensuar, neste caso, a dominação masculina e o arquétipo submisso e recatado da mulher.

\section{Referências}

ALMEIDA, K. D.; LUZ, N. S. da. Educação Sexual: uma discussão para a escola? Curitiba: Appris, 2014. 
ALVES, J. E. D. A Linguagem e as Representações da Masculinidade. Rio de Janeiro: Escola Nacional de Ciências Estatísticas / Instituto Brasileiro de Geografia e Estatística. Textos para Discussão 11, 2004.

APPLE, M. W. Currículo e poder. Revista Educação e Realidade, Porto Alegre, v. 14, n. 2, p. 46-57, 1989.

BALESTRI, R. Matemática: interação e tecnologia, volume 2. 2.ed. São Paulo: Leya, 2016.

BARROSO, J.M. Conexões com a matemática. Obra coletiva concebida, desenvolvida e produzida pela Editora Moderna. - 1.ed. - São Paulo: Moderna 2010.

BOURDIEU, P. A dominação masculina. Tradução Maria Helena Kühner. $15^{\mathrm{a}}$ ed. Rio de Janeiro: Bertrand Brasil, 2019.

BUTLER, J. Problemas de gênero: feminismos e subversão da identidade. 17 ed. Rio de Janeiro: Civilização Brasileira, 2019.

BUTLER, J. Corpos em aliança e a politica das ruas: notas para uma teoria performativa de assembleia. 2 ed. Rio de Janeiro: Civilização Brasileira, 2018.

CASAGRANDE, L. S.; CARVALHO, M. G. Educando as Novas Gerações: Representações de gênero nos livros didáticos de matemática. $29^{a}$ Reunião da ANPEd, Caxambu, Anais, Caxambu, M.G., 2006.

CENTURIÓN, M; JAKUBOVIC, J. Matemática nos dias de hoje, $6^{\circ}$ ano: na medida certa. 1 ed. São Paulo: Leya. 2015a.

CENTURIÓN, M; JAKUBOVIC, J. Matemática nos dias de hoje, $9^{\circ}$ ano: na medida certa. 1 ed. São Paulo: Leya. 2015b.

DOWLING, P. Gender, Class, and Subjectivity in Mathematics: A Critique of Humpty Dumpty. For the Learning of Mathematics, v. 11, n. 1, 1991, p. 2-8. Published by: FLM Publishing Association.

FOLHA DE SÃO PAULO. Ideologia de gênero é coisa do capeta, diz Bolsonaro na Marcha para Jesus. Disponível em: https://www1.folha.uol.com.br/cotidiano/2019/0 8/ideologia-de-genero-e-coisa-do-capeta-diz-bolsonaro-na-marcha-para-jesus.shtml. Acesso em 21 de ago. 2019.

FRISON, M. D. et al. Livro didático como instrumento de apoio para construção de propostas de ensino de Ciências Naturais. In: VII Encontro Nacional de Pesquisa em Educação em Ciências. Anais. Florianópolis, 2009.

GARCIA, T. M. F. B. Os livros didáticos na sala de aula. In: Tânia Maria F. Braga Garcia; Maria Auxiliadora Schmidt; Rafael Valls. (Org.). Didática, História e manuais escolares: contextos ibero-americanos. 1ed. Ijuí, RS: Editora Unijuí, 2013, v. 6, p. 69-102. 
GIOVANNI, J.R.; BONJORNO, J.R. Matemática uma nova abordagem: progressões, volume 2. 2.ed. São Paulo: FTD, 2011.

GODOY, E. V. Matemática no Ensino Médio: Prescrições das Propostas Curriculares e Concepções dos Professores. 2002. 244 f. Dissertação (Mestrado em Educação Matemática) - Pontifícia Universidade Católica de São Paulo, São Paulo.

GODOY, E. V. Currículo, cultura e educação matemática: uma aproximação possível? Campinas: Papirus Editora, 2015.

GODOY, E. V.; LIMA, Y. C.; MUSHA, F. D. A questão de gênero nos intramuros das aulas de matemática. In: Aparecido Francisco dos Reis; Vivian de Veiga Silva. (Org.). IV SIGESEX (IV Simpósio de Gênero e Sexualidade-Gêneros, Sexualidades e Conservadorismos: a Política dos Corpos, os Sujeitos e a Disputa pela Hegemonia dos Sentidos Culturais). 1ed.Campo Grande: Life Editora, 2019, v. 1, p. 285-294.

GRANBERG, D.; BROWN, T.A. The Monty Hall Dilema. Personality and Social Psychology Bulletin, v. 21, n.7, p. 711-723, 1995.

LINS, B. A.; MACHADO, B. F.; ESCOURA, M. Diferentes, não desiguais: a questão de gênero na escola. São Paulo: Reviravolta. 2016.

LOURO, G. L. Educação e docência: diversidade, gênero e sexualidade. Revista Brasileira de Pesquisa Sobre Formação Docente, Belo Horizonte, v.3, n. 4, p. 62-70, 2011.

LOURO, G. L. Pedagogias da sexualidade. In: LOURO, G. L. (Org.). O corpo educado: pedagogias da sexualidade. Belo Horizonte, MG: Autêntica Editora, 2019. p. 7-42.

MAIA, A. C. B. et al. Educação Sexual na escola a partir da psicologia históricocultural. Psicologia em Estudo, Maringá, v. 17, n. 1, p. 151-156, 2012.

MATRICARDI, C. (Org.). Projeto Lumirá: alfabetização matemática. São Paulo: Editora Ática, v. 2, $2^{\circ}$ ano, 2014.

MUSHA, F. D.; PORTELA, H. L. E. Gênero e Matemática: confluência ou dicotomia? Curitiba, 2018. Não publicado.

NANI, A. P. S. (org.). Aprender juntos: alfabetização matemática. São Paulo: Edições SM, v. 2, $2^{\circ}$ ano, 2014.

O GLOBO. Alunas "decoram" faculdade com frases machistas de professores. Disponível em:<https://oglobo.globo.com/sociedade/alunas-decoram-faculdade-comfrases-machistas-de-professores-1-19195015>. Acesso em: 8 de agosto de 2018.

PAULINO, W. Fifa aumenta a diferença de premiação entre as copas Masculina e Feminina. 2018. Disponível em: https://blogs.ne10.uol.com.br/torcedor/2018/10/26/ fifa-aumenta-a-diferenca-de-premiacao-entre-as-copas-masculina-e-feminina/.

Acesso em: 15 de maio de 2019. 
SILVA, J. F. Linguagem Sexista sobre a Perspectiva da Análise do Discurso: Olhares Esboçados em uma Revista Dirigida a Professores. Olhar de professor. Ponta Grossa, v.7, n.1, p. 77-83, 2004.

SILVA, T. T. A produção social da identidade e da diferença. In: SILVA, T. T. (Org.). Identidade e diferença: A perspectiva dos Estudos Culturais. Petrópolis: Vozes, 2009. p.73-102.

SILVEIRA, E. Projeto navegar: matemática. São Paulo: Moderna, v. 2, 2014.

SILVA, C. L. A.; GODOY, E. V. O programa nacional do livro didático: um olhar sociocrítico para a abordagem do conceito de função. Revista Paranaense de Educação Matemática, v. 7, p. 152-180, 2018.

VALERO, P.; SILVA, M. A.; SOUZA, D. M. X. de B. The curricular-toy, mathematics and the production of gendered subjectivities. In: Proceedings of the Tenth International Mathematics Education and Society Conference (MES10), 10, 2019, Hyderabad, India. Anais... Hyderabad, India

YOUSSEF, A.N.; FERNANDES, P.; SOARES, E. Matemática: ensino médio, volume único. São Paulo. Scipione 2005.

Recebido em janeiro de 2020.

Aprovado em março de 2020. 